ECONOMIC GROWTH CENTER

YALE UNIVERSITY

P.O. Box 208629

New Haven, CT 06520-8269

http://www.econ.yale.edu/ egcenter/

CENTER DISCUSSION PAPER NO. 975

\title{
Economics, Area Studies and Human Development
}

\author{
Gustav Ranis \\ Yale University
}

July 2009

Notes: Center Discussion Papers are preliminary materials circulated to stimulate discussions and critical comments.

This paper can be downloaded without charge from the Social Science Research Network electronic library at: $\underline{\text { http://ssrn.com/abstract }=1441379}$

An index to papers in the Economic Growth Center Discussion Paper Series is located at:

http://www.econ.yale.edu/ egcenter/publications.html 


\title{
Economics, Area Studies and Human Development
}

\author{
Gustav Ranis
}

\begin{abstract}
$\underline{\text { Abstract }}$
This paper suggests that area studies and economics have a better chance to be married successfully if we shift our attention from the exclusive emphasis on economic growth towards improvements in human development, especially the much broadened version of that concept. Different areas are shown to differ substantially in terms of the choices they make among the various independent dimensions of well-being and the various indicators within each dimension. The particular characteristics of each area play an important role in determining the choices societies make and the extent to which they are constrained by their initial conditions.
\end{abstract}

Keywords: $\quad$ Economics, Human Development, Area Studies

JEL Codes: O1, O2, O5 
As is well known, economics was the first of the modern social science disciplines to erect a rational choice machinery and try to approach the natural sciences by asserting the validity of universal maximizing behavior. Area studies, on the other hand, had their origin in the World War II "Chrysanthemum and the Sword"/"know your enemy" era - not immune from U.S. exceptionalism.

When considering the relationship between economics and area studies, we also need to recognize that economics itself is currently under attack and on the defensive. In particular, macro analysis, most relevant to the subject of this Conference, is presently out of favor, while micro-econometric analysis is definitely "in" and most of it quite unconcerned with the issues before us. What is generally left of possible relevance in macroeconomics are cross-country regressions a la Barro which, in their more sophisticated manifestations, include relatively crude institutional and geographic variables which, at best, can be called the beginning but not the end of wisdom, i.e., something intermediate is needed beyond such regressions and old-fashioned country studies. The micro-econometric work currently attracting the attention of much of the profession, on the other hand, is generally of excellent quality, quantitatively high tech in nature, but if area knowledge comes into play at all it is usually as a source for data collection to implement a model the conclusions from which are often quite evident ex ante.

Cross-country regressions are mercifully now on the decline but in-depth macro country studies relying on area studies information, the natural alternative, have not yet really emerged in full force. While there have been increasing challenges to the universalism of the machinery of neoclassical economics, emanating from an enhanced interest in institutions, behavioral and experimental economics, much of this remains 
something of a black box, reminiscent of Solow's technology "residual" and requiring more convincing theoretical and empirical meat on the bones. It should, therefore, be no surprise that there has been increased questioning of the usefulness of economics in the public policy arena.

The realization that the world is really not all that "flat," even in this era of globalization, is gaining ground. While other social sciences have traditionally tried to imitate the methodology of economics, if with a substantial lag, non-economists, especially those in political science, are now ahead of economists in terms of their willingness to move into that no-man's-land between the disciplines and in recognizing that cross-area convergence is but a convenient illusion. Psychology is now being applied to help explain differential responses to the current global financial and economic crisis. Can we expect the human development and capabilities approach to ride to the rescue, or at least to be helpful?

I am assuming that the overall human development (HD) concept is by now well known, if not universally acclaimed. Its basic premise is that economic growth, the variable usually deployed as a measure of human progress, is but a necessary means to an end, which is captured by the level of human development. Economic theory can then be applied to analyze the flow of resources, applied by governments and families, from economic growth to human development as well as to the feedback from improvements in human development back to economic growth.

The relevant measure of human development, of course, should not be restricted to the human development index which, as Amartya Sen, one of its parents, has himself clearly stated, represents but "rough and ready work" while "the real merit of the human development approach lies in the plural attention it brings to bear on developmental 
evaluation." In other words, a broadened HD approach leads us to capabilities and functionings which, unlike the case of GDP, will differ across countries and regions. Indeed, the need to combine general theories about human welfare with local peculiarities, histories and circumstances becomes much clearer when we replace economic growth with human development in any societal utility function.

In earlier work, in collaboration with Frances Stewart and Emma Samman, we extended the concept of human development beyond the Human Development Index by encompassing 11 important categories of the "good life" — drawn mainly from the philosophical literature, from Aristotle's Ethics onward ${ }^{1}$ - and proposed plausible indicators for each category. By eliminating indicators highly correlated with others in the same category and with the HDI itself we were left with 31 independent indicators.

It soon became clear to us that countries perform differently with respect to different dimensions of "the good life," and that is where area studies clearly come prominently into play. Areas of the world, indeed individual countries, depending on their histories, cultures and resources may, for example, choose to promote employment at the expense of social ties or political freedom at the expense of material well-being. It is of interest to know the extent to which observed patterns of country behavior are a matter of choice, of path dependency, of other constraints, or of history and culture.

Trying to identify a list of HD dimensions which are universally relevant would clearly be a futile pursuit. Even Sen has consistently refused to present an exhaustive list of his capabilities, i.e., those beings and doings that people value. To illustrate the point, one can, for example, identify a number of overlapping "wellness" categories,

\footnotetext{
${ }^{1}$ Rawls (1972), Finnis, et al. (1987), Doyal and Gough (1993), Nussbaum (2000), Narayan-Parker (2000) and Camfield (2005).
} 
e.g., bodily well-being, material well-being, mental well-being, spiritual well-being, employment, security, social relations, empowerment, and political freedom. As an example, picking four such dimensions which are reasonably quantifiable, i.e., under five mortality (representing the core HDI), employment, social relations, and political freedom, permits us to demonstrate the possible links which can be forged between universalist theory and specific area characteristics.

Such areas can be classified in the traditional way, i.e., Sub-Saharan Africa, Latin America, the Middle East, Southeast Asia and Central Asia, by their income level as defined by the World Bank, by their conflict or post-conflict characteristic, by whether they are land-locked, near the equator, near the water, have oil, etc. Our aim is to explore whether different country types behave differently with respect to various categories of "the good life" or whether we can observe convergence.

Our approach is as follows: we classify each region of the world with respect to each of our four indicators as medium, high or low relative to the interquartile range for that indicator. ${ }^{2}$ Our results clearly demonstrate that "all good things don't always go together." Given that HD is now made up of many types of capabilities, some aspects may be favored in some circumstances and others in other areas and at other historical times. About half the entire sample of countries we looked at indeed showed a particular deficiency or superiority in one category or another.

More generally, alternative patterns of behavior are likely to be dictated by country political choices, by current constraints, or indeed by culture and history. Our findings suggest that many poor countries are doing badly on the economics and basic

\footnotetext{
2 The full methodology is presented in "Country Patterns of Behavior on Broader Dimensions of Human Development" in K. Basu and R. Kanbur (eds.)Arguments For A Better World: Essays In Honor Of Amartya Sen, Volume II: Society, Institutions, and Development, Oxford University Press.
} 
HD categories but do better on the political and social categories. Is this a matter of choice or necessity? There are three possibilities: (a) countries indeed choose to enhance social welfare and political freedom at the expense of economic progress and basic HD; (b) they choose to enhance social and political dimensions despite unavoidably weak economics and basic HD; or (c) what results is not so much societal choice but the consequences of various dimensions of the initial conditions.

It seems to me that for most cases (a) is unlikely, given the generally expressed desire to promote economic growth and basic HD (e.g., to meet the millennium development goals) and the fact that there is no obvious major resource cost entailed in improving performance on social and political aspects. It seems more likely that a weak performance on economic and basic HD is a consequence of deep constraints including weak government capacity, heavy inherited indebtedness and a history of violent conflicts - and not, at least at very low income levels, a matter of choice. Given the low resource costs of doing well on the social and political dimensions, this is a clear choice even in the context of low income economies. One can, of course, further unravel these two categories, social and political, to consider which indicators are likely to be chosen and which are likely to be determined.

To provide an example, social relations, at least as commonly interpreted and measured, are partly a matter of income distribution and partly a matter of having close social and family relations and tolerant neighbors. The male suicide rate can be used as an indicator to reflect how stressful life is. The income distribution variable can be influenced (if with difficulty) by the government. The other indicators probably can also be influenced - for example, if physical security is very low because of poor policing, social relations may be worse; and policies towards education, the media and 
discrimination may contribute to improving aspects of social relations. But, to a considerable extent, these dimensions are the outcome of underlying social and economic forces, not government policy. It seems likely that they (particularly the ones involving social relationships) depend in part on the size of the places people live in (i.e., being stronger in rural than in urban communities), and on the time people have available (i.e., stronger when people are less busy). This suggests that poor countries that are socially "high" are in this category mainly because of their superior income distribution, while areas that are socially "low," in contrast, typically have good achievements across the social indicators.

Putting all this together, it suggests, if somewhat speculatively, that one might expect the social side to do better relative to economic aspects at lower levels of urbanization and employment - i.e., at lower levels of development. This is broadly what we found, and I would argue that it is more a matter of the stage of development and less of governments' or people's choices. Other policy conclusions follow. For example, the consistently deficient performance across our four categories by countries suffering violent conflict indicates, not surprisingly, that overwhelming priority has to be given to policies focused on it.

The political category, to cite another example, includes collective political violence which is sometimes chosen, but can also happen as the result of exogenous forces. It also includes the rule of law indicator, over which governments have some influence but which evolves slowly, with inputs from civil society as well as government; it moreover includes political and civil liberties which is the one indicator that can be said to be chosen, albeit, especially in the case of low income countries, usually under the influence of the donor community. Thus, as far as the politics category is concerned, 
the fact that some poor countries do better here than on other categories may be due to choices they make, not at the expense of doing well elsewhere, but as something they can choose without having to sacrifice other aspects.

The experience of middle income countries partly supports what has been said above and partly indicates the wider range of choices open to middle income countries. In the first place, many are socially deficient. This does suggest that this aspect tends to lag as development proceeds: perhaps for the reason given above, i.e., people become more urbanized and disconnected and have less time, while government efforts that might compensate for this, through policing and redistributive policies, are not always in place or effective.

The middle income countries also show considerable variation in the political category, with two-thirds coming under the "high" and one-third under the "low" label. This suggests that countries make different choices in this category - but may, of course, also be constrained by history. The influence of history is most clearly demonstrated by the special position of the East European transition countries which are categorized as "low" precisely because of their past, yet currently show a rather balanced performance. One might expect them to be high on basic HD, with heavy emphasis on health and education, but to be politically and possibly economically deficient, and socially mixed - good on income distribution and possibly poor on social relations.

The lack of systematic connections between overall life satisfaction and performance on our four selected dimensions of HD could be interpreted in two very different ways. One would be to argue, along with Layard (2005), that life satisfaction (or "happiness") should be the overriding single indicator of success and hence the sole 
objective of development. The lack of correlation with other measures of performance might then be taken as a good reason for adopting this position. Alternatively, one might argue, along with Amartya Sen, that development is about expanding choices, which is better captured by our four dimensions than by a single somewhat arbitrary measure of life satisfaction; moreover, to the extent that life satisfaction indicates that people's expectations adapt to their circumstances, it becomes a poor indicator of area performance and a false guide to development. ${ }^{3}$ I tend to take that view, but perceptions are also important, and a consistently low appreciation of life satisfaction is a matter which should concern decision-makers, along with our more objective indicators.

In conclusion, the several possible patterns of behavior discussed indicate that, while some areas may be constrained by history, culture and initial conditions, even they also manage to make abundant choices among the different dimensions of wellbeing. Even low income countries can do well in all categories. And even high income countries can achieve poorly in some. The first gives reason for optimism, the second for pessimism. But, in all cases, in order to get to the "bottom line" on human welfare we need a marriage between economic theory extended to human development and a deep knowledge of individual areas.

\footnotetext{
${ }^{3}$ Sen $(1979,1985,1987,1993,2002)$ takes this view.
} 


\section{$\underline{\text { References }}$}

Camfield, L., 2005. Researching quality of life in developing countries. ESRC Research Group on Well-being in Developing Countries Newsletter, 3 (1).

Doyal, L. \& Gough, I., 1991. A Theory of Human Need. Basingstoke: Macmillan.

Finnis, J., Boyle, J.M. \& Grisez, G., 1987. Nuclear Deterrence, Morality and Realism. Oxford: Clarendon Press.

Narayan-Parker, D., Chambers, R., Shah, M.K. \& Petesch, P., 2000. Voices of the Poor: Crying Out for Change. New York, N.Y.: Published for the World Bank, Oxford University Press.

Nussbaum, M.C., 2000. Women and Human Development: The Capabilities Approach. Cambridge: Cambridge University Press.

Ranis, G., Stewart, F. and Samman, E., 2006. "Country Patterns of Behavior on Broader Dimensions of Human Development," in K. Basu and R. Kanbur (eds.) Arguments For A Better World: Essays In Honor Of Amartya Sen, Volume II: Society, Institutions, and Development, Oxford University Press.

Rawls, J., 1972. A Theory of Justice. Oxford: Clarendon Press.

Sen, A.K., 1979. Utilitarianism and Welfarism. The Journal of Philosophy, 76 (9), p. 463489.

Sen, A.K., 1985. Well-being, Agency and Freedom. The Journal of Philosophy, LXXXII (4), p. 169-221.

Sen, A.K., 1987. The Standard of Living. Cambridge, Cambridge University Press.

Sen, A.K., 1993. Positional Objectivity. Philosophy and Public Affairs, 22 (2), p. 126145.

Sen, A.K., 2000. A decade of human development. Journal of Human Development, 1 (1), p. 17-23.

Sen, A.K., 2002. Health: Perception versus Observation. British Medical Journal, 324 (7342), p. 860-861. 